\title{
BMJ Open How do participant experiences and characteristics influence engagement in exercise referral? A qualitative longitudinal study of a scheme in Northumberland, UK
}

Coral L Hanson, ${ }^{1,2}$ Emily J Oliver, ${ }^{2,3}$ Caroline J Dodd-Reynolds, ${ }^{2,3}$ Linda J Allin ${ }^{4}$

To cite: Hanson $\mathrm{CL}$, Oliver EJ, Dodd-Reynolds CJ, et al. How do participant experiences and characteristics influence engagement in exercise referral? A qualitative longitudinal study of a scheme in Northumberland, UK. BMJ Open 2019;9:e024370. doi:10.1136/ bmjopen-2018-024370

- Prepublication history and additional material for this paper are available online. To view these files, please visit the journal online (http://dx.doi. org/10.1136/bmjopen-2018024370).

Received 24 May 2018

Revised 9 October 2018

Accepted 17 December 2018

Check for updates

(C) Author(s) (or their employer(s)) 2019. Re-use permitted under CC BY-NC. No commercial re-use. See rights and permissions. Published by BMJ.

For numbered affiliations see end of article.

Correspondence to

Dr Coral L Hanson;

c.hanson@napier.ac.uk

\section{ABSTRACT}

Objectives Exercise referral schemes (ERSs) are internationally widespread. This study aimed to gain an insight into differential engagement through understanding participant experiences of patients referred by healthcare professionals to one such scheme in the UK.

Design The study employed a qualitative longitudinal approach using semistructured interviews, with results reported using Consolidated criteria for Reporting Qualitative research guidelines.

Setting Two leisure centres providing an 'emerging bestpractice' ERS in northeast England.

Participants Referred patients $(\mathrm{n}=11)$, who had not yet commenced the scheme, were recruited on a voluntary basis. Seven females and four males, with a range of noncommunicable diseases, such as cardiovascular disease, mental health issues, diabetes, overweight/obesity and musculoskeletal problems, participated.

Intervention 24-weeks, two times per week, of supervised exercise sessions and three one-to-one assessments (prescheme, 12 weeks and 24 weeks) for patients referred from primary and secondary care. Primary outcome measures Two longitudinal semistructured interviews, prior to commencement and 12-20 weeks later, were thematically analysed using the framework approach. Analysis comprised seven stages: transcription, familiarisation, coding, development and application of an analytical framework, charting data using a matrix and interpretation of data. Interpretation went beyond descriptions of individual cases to develop themes, which identified and offered possible explanations for differing participant experiences.

Results Three overarching themes emerged. First, 'success', with engaged participants focused on health outcomes and reported increases in physical activity. Second, 'struggle', with short-term success but concerns regarding continued engagement. Participants reported scheme dependency and cyclical needs. Finally, 'defeat', where ill health, social anxiety and/or poor participation experience made engagement difficult.

Conclusion Some success in engaging those with noncommunicable diseases was reported, resulting in positive effects on health and well-being. The study highlights complexity within ERSs and inequality of access for those with challenging health and social circumstances.
Strengths and limitations of this study

- This study advances the predominantly quantitative literature on participant adherence to exercise referral by using a longitudinal qualitative design to gain a deeper understanding of the experience of patients with non-communicable diseases referred to an exercise referral scheme (ERS).

- The study provides insight into the complexity of ERSs, with the study population reporting a range of participation experiences including some who did not successfully engage with the ERS.

- The study was unable to engage some of the original participants in second interviews, meaning that the experiences of some who may have been least wellserved by the intervention are unknown.

- The sample of participants were recruited from only one, although large scale, ERS, meaning that findings relate to this particular scheme and sample.

- Qualitative interviews can only provide information on what participants recall or are prepared to reveal about their perceived experiences within a particular interview context, meaning that the potential for recall bias is always present.

Improved, or different, behaviour change support is required for referrals finding engagement difficult.

\section{INTRODUCTION}

Regular physical activity (PA) has a beneficial effect on cardiovascular disease risk, diabetes, some cancers and all-cause mortality. ${ }^{1}$ The global cost of inactivity to healthcare in 2013 was estimated to be 53.8 billion international dollars, ${ }^{2}$ with increasing PA levels a high priority to reduce non-communicable diseases. ${ }^{3}$ Participation in PA has been widely described in terms of demography, with inequalities apparent. ${ }^{4}$ For example, there is an inverse relationship between $\mathrm{PA}$ and indicators of disadvantage such as 
socio-economic status ${ }^{5}$ and multiple co-morbidities. ${ }^{6}$ In order to have the greatest impact, PA promotion initiatives must therefore consider the context, and barriers and facilitators to engagement specifically in disadvantaged populations.

Emerging evidence indicates that current PA programmes can fail to engage or retain more disadvantaged participants. Lower socio-economic status, and increasing number of health conditions, medications and depressive symptoms have been reported to negatively predict adherence. ${ }^{7}$ Factors affecting participation are complex. Personal and social factors such as positive childhood PA experience and social support for PA are known to positively influence activity levels. ${ }^{8-12}$ Understanding how and why existing programmes engage, or do not engage, participants with differing personal circumstance can inform future equitable practice.

An exercise referral scheme (ERS) is one option for health professionals to promote PA for those with non-communicable diseases. ${ }^{13}$ Such schemes are internationally widespread, existing for example, in the UK, ${ }^{14}$ Denmark, ${ }^{15}$ Spain ${ }^{16}$ and Mexico. ${ }^{17}$ In the UK, leisure providers usually deliver ERSs, directing participants into 10-24 weeks of supervised PA. The present study focused on one large-scale ERS identified as emerging best practice by Public Health England..$^{18}$ Although ERSs are broadly aimed at those with non-communicable diseases, there is limited understanding of effective targeting. Exploring whether sub-groups of participants are more or less likely to engage, therefore, has value in informing practice. ${ }^{19}$ This is important because cost-effectiveness analyses indicate that ERSs need to reduce costs by $60 \% \cdot{ }^{20}$ However, lack of evidence about effectiveness for participant sub-groups may have resulted in an underestimation of benefits. Indeed, the UK National Institute for Health and Care Excellence has identified a requirement to understand better what ERS elements work best and for whom. $^{21}$

To implement successful and equitable ERSs, there is a need to better understand who existing programmes work or do not work for. Demographic evidence contributes some knowledge, ${ }^{20}{ }^{22}$ but a more in-depth analytical approach is required to increase the understanding of other factors influencing engagement. This longitudinal qualitative study aimed to gain an insight into differential engagement through understanding participant experiences of an ERS.

\section{METHODS}

The study employed a longitudinal qualitative design to explore experiences of participants referred to the Northumberland ERS. Results were reported using the Consolidated criteria for Reporting Qualitative research guidelines. ${ }^{23}$ Overarching themes, encompassing a variety of participants with differing social contexts and motives for referral, were established.

\section{Context}

The ERS received primary and secondary care referrals for those with cardiovascular disease, overweight/obesity, mental health issues, metabolic disease, and musculoskeletal, respiratory and neurological conditions. Previous analysis $(n=2233)$ reported a significant increase in self-reported PA for those who adhered, with being aged $\geq 55$ years a predictor of successful engagement. ${ }^{24}$ Scheme design was based on the transtheoretical model. ${ }^{25}{ }^{26} \mathrm{It}$ consisted of three one-to-one consultations and 24 weeks of PA sessions two times per week (figure 1). During consultations, participants chose which PA sessions to attend. Those who did not attend activity sessions for 1 week were contacted by telephone or post. Each ERS session cost $£ 3.40$. Participants could purchase a discounted direct debit fitness and swimming membership while taking part and after completion (£24.00/month). Staff held an industry standard exercise referral qualification.

The study took place in two of nine leisure centres providing the ERS. Referrals to these leisure centres were representative of the demographic spectrum of participants. This included a broad adult age range, males and females, and a range of economic circumstances and medical conditions. All those referred to the two leisure centres during May and June $2013(\mathrm{n}=102)$ were eligible to take part.

\section{Patient and public involvement}

Previous binary logistic regression analysis of demographic and personal factors associated with engagement and adherence to the ERS ${ }^{24}$ informed the study. Participants were not involved in study design. A summary of results was available for study participants.

\section{Sample}

The Northumberland ERS provided a convenient sample, ${ }^{27}$ which was easily accessible to CLH, due to her employment by the scheme provider as a strategic manager. All those invited to attend initial consultations during the first 2 weeks of the recruitment period $(n=25)$ received an invitation to participate. During initial telephone contact, ERS staff informed referrals that the study consisted of two semistructured interviews about their ERS experience. The first was conducted prior to starting, and the second later in the 24-week period. Postal information was sent to interested referrals, who signed and returned the consent form to register for the study. ERS staff arranged interviews and the researcher had no access to personal details until consent was given. Participants were informed that the researcher was an employee of the scheme provider and that a research objective was to improve service delivery. There was no obligation to take part and ERS involvement was not dependent on this decision. Eight of those initially invited agreed to participate. Later sampling was purposeful, based on developing themes (those with multiple medical conditions and referrals under 50 years old) from earlier initial interviews. ${ }^{28}$ ERS staff were asked to invite referrals with 


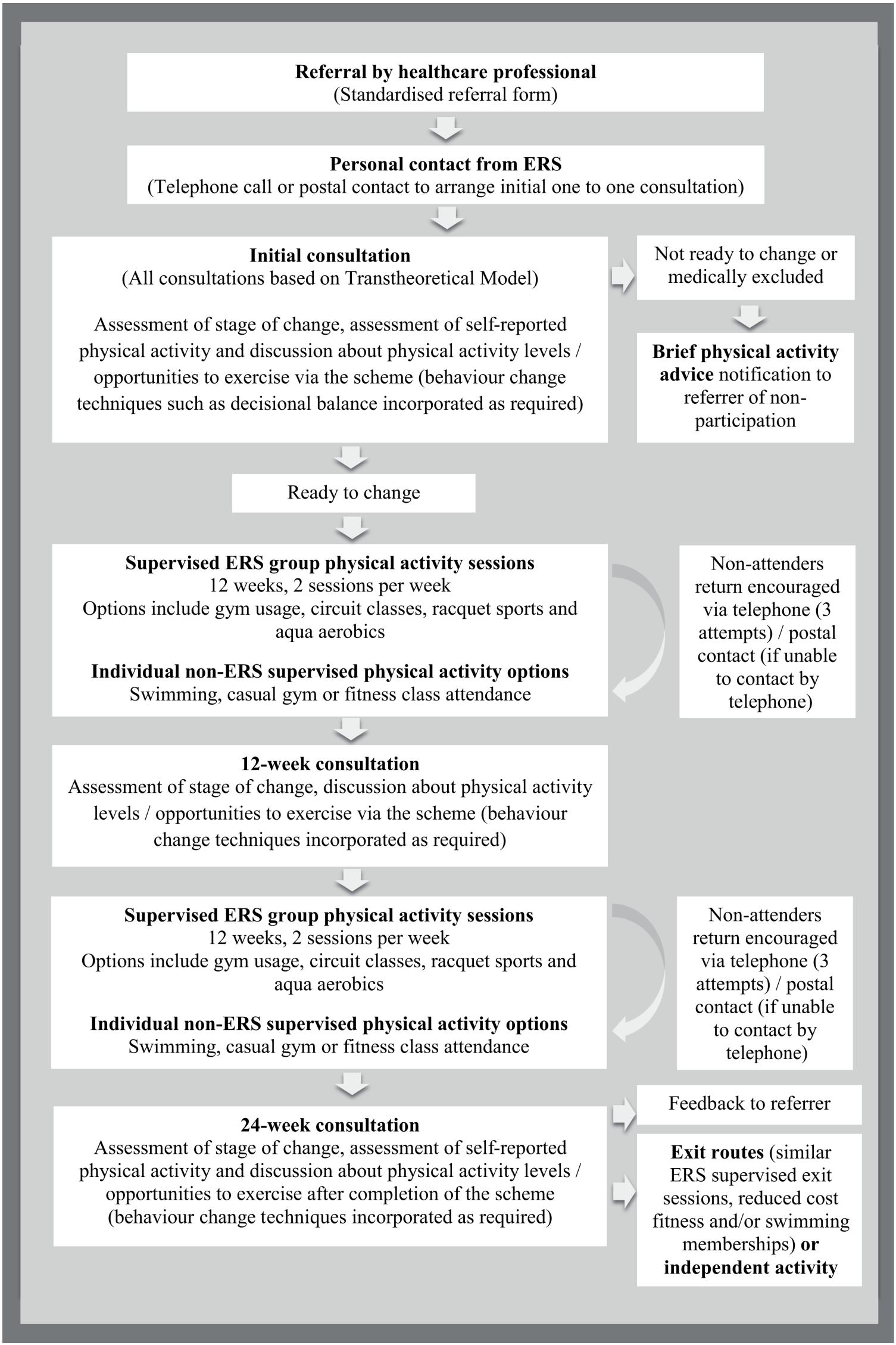

Figure 1 Exercise referral scheme process. 
only these characteristics to take part later in the study. Recruitment continued until no new overarching themes developed from initial interview analysis.

\section{Data collection and analysis}

Data were collected via two longitudinal semistructured interviews conducted between May and December 2013, which were audio-recorded and transcribed verbatim. CLH, a PhD student, conducted all interviews. CLH had 15 years' experience of working for the ERS but was not involved in delivery during the study. Prior to undertaking interviews, CLH completed qualitative interviewing training and received mentoring from LJA, an experienced qualitative researcher. Initial interviews took place in private immediately prior to initial consultations at the participants' leisure venue. One pilot interview using a semistructured guide (online supplementary file 1) was conducted and analysed by CLH and LJA. Topics covered included PA history, motivators for referral, perceptions and expectations of the ERS, and perceived barriers and facilitators to taking part. The guide remained unchanged and the pilot interview deemed suitable for study inclusion. Initial interviews focused on circumstances leading to referral and perceptions of the ERS. Second interviews, which took place 12-20 weeks later, focused on participation or non-participation experiences (online supplementary file 2). Participants checked attendance at sessions with scheme staff and reported this during second interviews. The duration of individual interviews ranged from 22 to $62 \mathrm{~min}$ (median: $48 \mathrm{~min}$ ). Participants checked transcripts for accuracy. Detailed field notes focused on participants' social context, the quality of the interaction and potential researcher bias due to insider knowledge.

Interviews were subject to thematic analysis using the framework approach. ${ }^{29}$ The use of pseudonyms ensured anonymity. CLH and LJA familiarised themselves with transcripts through reading and re-reading, and by listening to audio-recordings to check accuracy. Using manual processes and Microsoft Excel to organise data, they openly recorded preliminary concepts and patterns for three transcripts. After discussion between all authors $(n=4)$, the establishment of agreed codes formed an initial analytical framework. Three more transcripts were analysed before refinement and finalising of the framework to allow comparison within and across all cases. The creation of a matrix allowed for the mapping and exploration of connections within and between participants and categories. During interpretation, analysis went beyond descriptions of individual cases to develop themes identifying and offering possible explanations for types of ERS experience. Participants did not provide feedback on findings, but themes were presented to ERS staff via a workshop. This did not result in changes to the results.

\section{RESULTS}

\section{Participant characteristics}

In total, 15 referrals took part in initial interviews and 11 completed both interviews. Only participants who completed both interviews were included in the final analysis (table 1). Four participants did not complete the second interview. Two participants responded stating that they had dropped out and did not have time for the interview due to a new job or caring commitments. The other two did not respond. Three of the four were under 50 years old.

\section{Overarching themes}

Three overarching themes emerged, each conveying a different referral experience (figure 2).

The first was success, with motivated participants focused on health outcomes. The second was described as struggle, with some level of short-term success. Cyclical changes in circumstances such as health status, and overall concerns regarding continued engagement were evident. The final theme centred on defeat, where ill health, social anxiety and/or poor experiences of participation made engagement difficult or unsuccessful. Short excerpts from transcripts give an indication of typical experience, with [...] signifying the joining of different sections. A participant case study illustrates each theme in more depth.

\section{Success: increased PA and improved health}

Success illustrated how the ERS worked very well for some, with sub-themes of improved health, increased PA and support. These participants tended to have had positive early experiences of sport and were motivated to improve or maintain health. Participation was mainly enjoyable, with peer and/or staff support being important attendance facilitators. Julie highlighted the 'very helpful 'staff and how 'enjoying Pilates has motivated me to be coming more.' Although personal goals, for example weight loss, were not always as anticipated, the experience was rewarding and there was a celebration of success. There was an expectation that activity would continue via signposted exit route sessions or independent exercise: I will just come on my own. They (other participants) have finished but they still come at the same time' (Patricia).

This theme is illustrated by Alice. She had completed cardiac rehabilitation prior to starting:

Alice: I loved sport, I used to cycle to work, then I started doing yoga, but I also like aqua fit, and I love walking around. I couldn't believe when I had a heart attack. [...] You have this fear, I don't walk anywhere where I'm going to fall down and nobody's going to see us. [...] I feel confident about the scheme. I'll move straight on (from cardiac rehabilitation). [...] I'm overweight; I've got to lose at least a stone. [...] You've got to use it or lose it, I've always believed that.'

During her second interview, Alice reported 91\% attendance and was very positive. Staff and social support were important in encouraging adherence:

Alice: I've really enjoyed it, I feel much healthier again, and I've made loads of new friends. I think the most important thing is I feel that I have got my confidence back. It has definitely lifted all that was frightening. [...] I haven't lost weight but I haven't put 

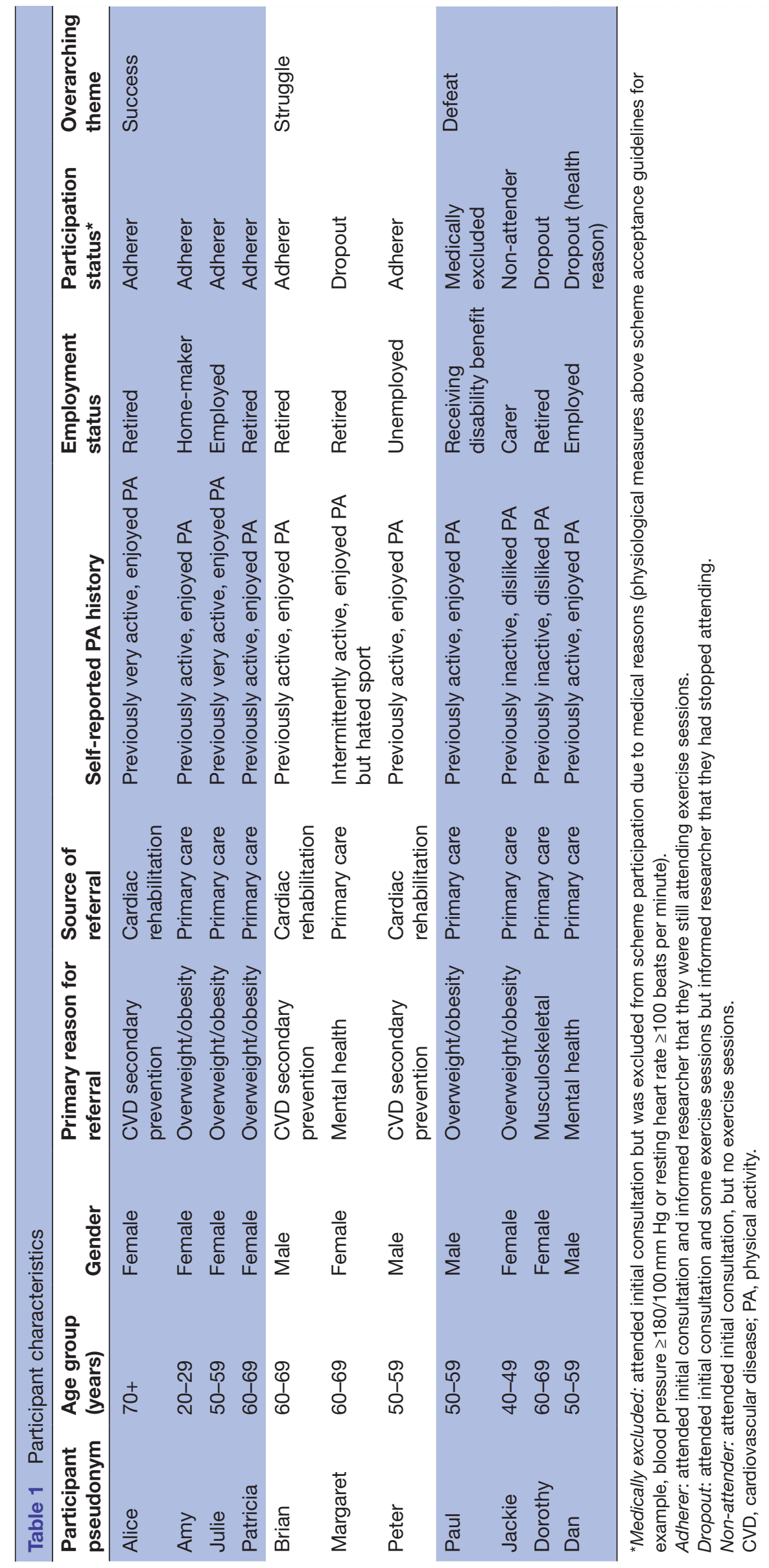


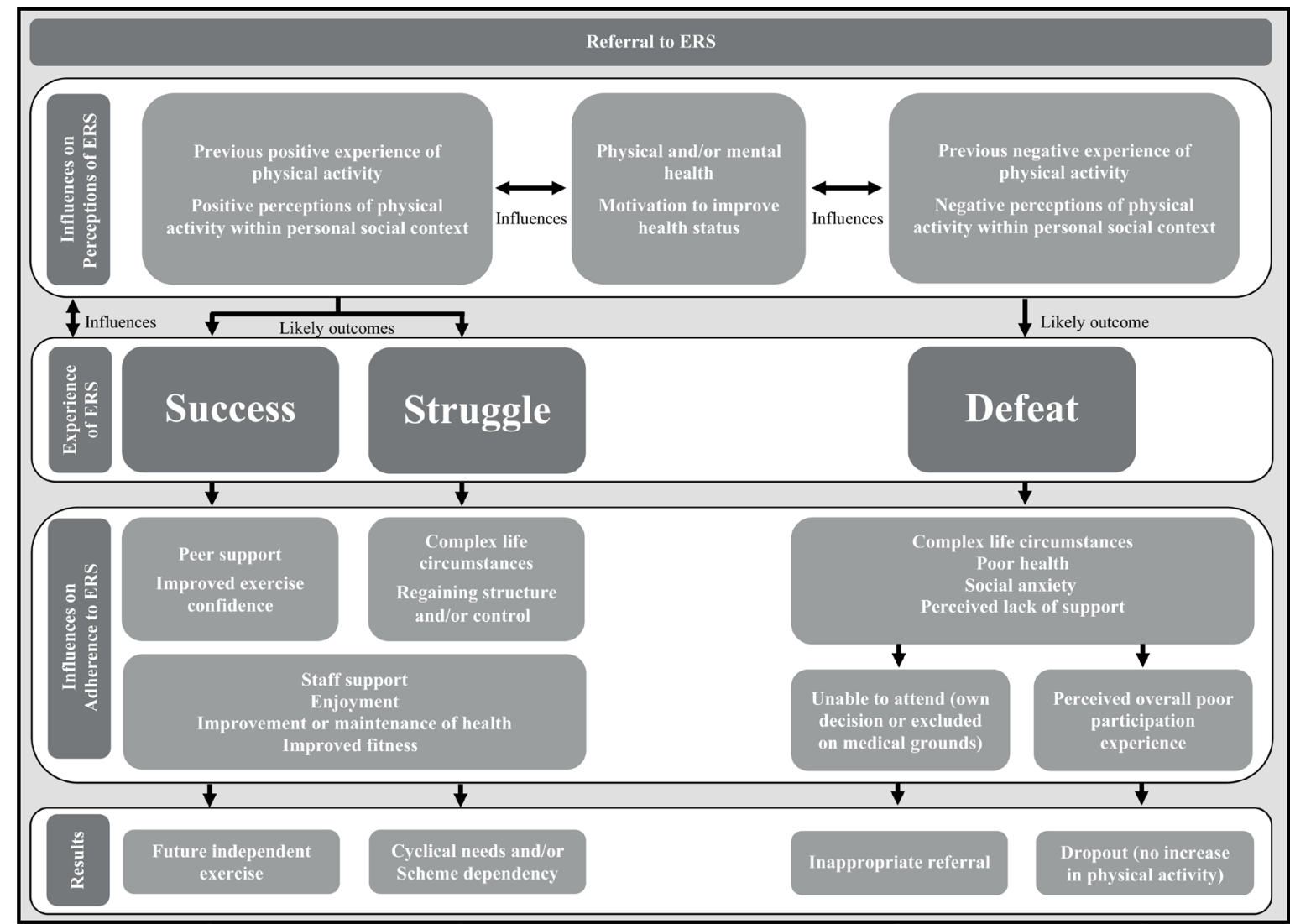

Figure 2 Thematic analysis of exercise referral scheme experiences.

any on. I am more content with my life again. More realistic. [...] I love the class, and I like the talking. Yes the mouth exercises, they are very good. [...] It makes you feel as though you belong in a club. [...] (Staff member) is full of fun as well. She does push you along.'

Within the theme of success, there were elements of struggle. Before starting the scheme, there were concerns about how perceived physical limitations and personal situations would affect attendance. Amy discussed self-esteem issues and how she made sure that I have got someone with us because I don't feel very confident going out by myself'.

Participants described using social comparisons ${ }^{30}$ to make judgements about their personal situation. Both upward and downward comparisons positively reinforced participation. For example, Amy developed positive views of older people's fitness, which encouraged her to do more: I've seen what they have got their treadmills on and I'm thinking, I'm only lower than them, I'd best turn it up.' Overall, there was a steady improvement in perceptions about ability to be active, and the associated health and social benefits. Enjoyment was both an important facilitator of success and a positive outcome of participation.

\section{Struggle: cyclical needs and scheme dependency}

Struggle illustrated how the ERS worked in the short term for some but highlighted that different approaches, or additional measures, may be necessary to encourage sustained increases in PA. Sub-themes of cyclical needs, scheme dependency and multiple barriers indicated that this theme was more complex than success. Resulting experiences were more divergent, with difficult life circumstances and/or complex health conditions influencing participation. For these participants, frequently life events had caused a breakdown of their social order (e.g., the death of a loved one or loss of a job), and the ERS enabled a regaining of structure and control. Strugglers perceived the scheme as a way to get lives back on track' (Margaret). This, when combined with complex health problems, meant disengagement could be difficult. Brian, a widower with depression and a history of myocardial infarction, had trouble with my left foot, I am partially blind now, diabetic'. He reported a lack of confidence to move on, indicating scheme dependency: I'm letting (staff member) set my programme. I might jigger myself up. The scheme is fine. It's ideal. I've been asking him can I stop in it?' Margaret, in contrast, felt that her mental health had improved, so she no longer needed to attend but recognised that this was cyclical, and that she may need future support.

Within struggle, participants reported increased PA and health gains I feel 100\% better' (Brian); however, longer-term positive continuation post-scheme appeared unlikely.

Peter's experiences illustrate the theme of struggle. For him, social circumstance was particularly influential. His 
attendance was sporadic ( $63 \%$ of potential sessions). He was unemployed at his first interview and saw a potential return to work as an adherence barrier:

Peter: 'Well I don't know exactly what is going to happen. I'll just see what it is and how it goes. If I enjoy it, I will stick with it as long as I can. [...] If I find work, I would stop attending.'

During his second interview, it was difficult to gauge his enthusiasm due to his natural reticence: I come because it is there and it's available. Or I would be just moping around the house all day doing nothing. 'His intermittent attendance was due to a work-related course and a short period of employment. Cost was an issue:

Peter: 'It's pretty hard because I have got no wages coming in. I've just got Job Seekers Allowance and that doesn't even pay my mortgage, so money is really tight. I did have a little insurance but that money has now run out and I really am starting to struggle. It is fairly cheap, but saying that, when you haven't got a lot of money coming in then it is a lot of money to pay out.'

Peter stated he would continue to attend until he found employment, when he might try and come with my partner and play badminton once or twice a week. 'His enthusiasm for this appeared to be lacking and therefore long-term change in PA was unlikely.

\section{Defeat: inappropriate referral or poor participation experience}

The third theme was defeat. Within this, sub-themes of poor health, social anxiety and poor participation experience were apparent. Some participants never attended an exercise session, being medically excluded (Paul), prevented by ill health (Dan) or social anxieties (despite telephone support):

Jackie: The thought of coming here on my own, with nobody else, I like staying in my comfort zone ...'(staff) phoned; she says about the sessions and that... and I was being honest with her... so she left it a couple of weeks and then phoned back and she says... would you not like to come along by yourself? And I went no.'

For others, poor participation experience (Dorothy) indicated weaknesses in scheme delivery. This group was defeated by the barriers faced, they felt ostracised from participation. There was a sense of failure and, for some, shame. For these participants, the ERS did not work.

This theme is illustrated by Dorothy, who had been previously referred to the scheme on two occasions. On the first occasion, she completed the scheme but did not continue via signposted exit route activities because her friend stopped attending. On the second occasion, she dropped out due to a problem with her foot. She did not like PA:

Dorothy: 'At school I wasn't very good at PE. I never liked it very much, only did what I had to do. [...] I've been to be the scheme twice before; other than that I don't think I really did any exercise. [...] I've got a real problem with my back. I'm sort of hoping that if I do exercise it will strengthen the muscles in my back and I will be able to do more things.'

During her second interview, Dorothy described how she felt unable to cope with the sessions due to back pain:

Dorothy: I did tell her that I'd got a back problem and I was waiting for these injections, but she said 'well start'. [...] I was quite disappointed because I couldn't do much of what they was asking us to do. It was a class and it was where you do sort of aerobics first and then go to all these sort of stations. I found it really hard.'

Discussing one session, she described a lack of staff support: She just said do what you can do and if you can't do whatever it is, just keep your feet moving.' This contrasted with her experience with another staff member: She knew when you couldn't do it and she would give you an alternative. So she was really good but she was only there once.'

The scheme had a system of telephone support, but in Dorothy's case, implementation appeared to be lacking:

Dorothy: I 'phoned in several times to explain. I left messages but nobody got back to me. I think if maybe someone had 'phoned me back and said 'well come in and you can do the things a different way' it might have encouraged me to go back in again.'

Dorothy raised delivery issues and highlighted the need for a better understanding of protocol implementation by staff. She was very upset by her experience, stating 'It makes you feel like a failure sometimes. I don't think I could go to the doctors and say 'I failed last time can you refer me again'?' Her experience was complex, however. She felt unable to access the peer support described by those who engaged successfully. During her first interview, Dorothy described how she found socialising difficult: I'm not really a good mixer so I find it quite hard.' During her second interview, she reported that the group felt unwelcoming: She was really nice, one lady that was there. Apart from her, I don't think any of the others were welcoming or said anything. Like I said they got into their little twos or threes or whatever.'

Lack of social confidence contributed to dropout, although in Dorothy's case it does not appear to have been the primary influence. Defeat illustrates how some participants may struggle to access the peer support identified by others as an important facilitator for adherence.

\section{DISCUSSION}

The purpose of this study was to understand the experiences of an ERS to give insight regarding what worked, or did not work, to encourage engagement, and for whom. This is important because existing literature questions 
ERS effectiveness, ${ }^{20} 22$ without exploring adequately how to focus implementation to better personalise support. Three overarching themes emerged. First, success, with engaged participants focused on health outcomes. Second, struggle, short-term success but with concerns regarding continued engagement. Finally, defeat, where illness, social anxiety and/or poor participation experience prevented engagement. Within the identified themes, similarities in factors affecting engagement and non-engagement were evident. For those who experienced some measure of success, there were shared enablers such as peer support, achievable and enjoyable activities, and staff knowledge and support. These are reflected to some extent in systematic review findings of engagement facilitators for ERS. ${ }^{31}$ What this paper adds is insight regarding whom these facilitators worked best for within the ERS context. Specifically, participants, who were able to access social support, had positive previous experiences of PA, and were motivated by improving or maintaining their health. Participants often described success in terms of improvements in mental health and self-esteem, perceptions about ability to be active and the social benefits of participation. Social and psychological benefits were perceived to be as meaningful as measurable physical health benefits, similar to other reported findings. ${ }^{32}$ Success illustrated the value of exercise referral for some participants with non-communicable diseases. This was not universal, however. The study highlighted unequal abilities to access the scheme, along with differing support requirements, which suggests the need to provide more tailored support for some. The issues identified are reflective of other studies examining barriers to PA irrespective of the presence of a medical condition. $^{711}$

Adults with complex lives embarked on the ERS with expectations of positive changes in health. While ERS delivery training courses include elements of behaviour change, the training does not appear to be sufficient preparation for staff to deal with identified complex psychological barriers. Indeed, the high levels of responsibilities that fitness professionals undertake have led to concerns about adequacy of education and training. ${ }^{33}$ Further development of behaviour change elements within national occupational standards for promoting PA could partially address matters. This represents only part of the problem, however. This study illustrates how a 'one-size-fits-all' model does not adequately cater for the complex range of referrals received. Indeed, the existing model of universal referral to a common programme is potentially setting such schemes up to fail. This is because current measures of success are typically quantified as uptake and adherence, ${ }^{34-36}$ and/or self-reported changes in PA. ${ }^{15} 37$ Regardless of suitability, providers may feel obliged to 'shoehorn' referrals into schemes if the continuation of funding is reliant on achievement of such key performance indicators. This type of approach fails to consider the complex health and social circumstances of ERS participants, leading to an inadequate focus on what works and for whom.
In the case of ERS, there is a need to understand what different approaches are required to support change for those experiencing struggle or defeat. The themes presented in this study may resonate with ERS commissioners and providers and should encourage reflection of approaches to support. Success can reinforce good practice while highlighting potential improvements. Struggle can initiate conversations about alternative delivery for those who require more or different support in order to make sustained behaviour change. This may include mechanisms for cyclical support to re-engage those who relapse into inactivity and 'weaning' to reduce ERS dependency. Finally, defeat can initiate conversations about appropriate referrals, improvements to existing provision and alternative models of care. At a broad level, approaches may include support from multiple agencies, ${ }^{38}$ the use of technology ${ }^{39}$ or broader system change. ${ }^{40}$ Promisingly, there is emerging evidence of practice with the potential to better support patients with struggle or defeat-style narratives. Those with poor health may benefit from individualisation of exercise, ${ }^{41}$ those with social anxiety from more online delivery and support, ${ }^{42}$ and the complex needs of patients are more likely to be catered for appropriately with increasing use of scheme co-production. ${ }^{43}$ Calls at national policy level for better use of triage or a 'stepped approach to delivery' ${ }^{21}$ may further assist with both enhancing support for those with challenging circumstances and modifying or reducing it for those that risk becoming scheme dependent. Testing the effectiveness of these ideas should be a priority for future research.

\section{Methodological considerations}

Qualitative analysis is inherently subjective since it is influenced by the assumptions, beliefs and biases of the researcher. ${ }^{44}$ In this case, the researcher was experienced in the management and delivery of the ERS studied. Potential biases were explored by the use of reflective field notes and in group discussions with all authors. Particular attention was paid to how existing knowledge may have affected discussion with participants and interpretation of results. That said, while in the past an outsider, objective stance was considered desirable in research terms to guard against identification, insider insight can now be considered legitimate and desirable due to the potential for increased empathy with participants. ${ }^{45}$ After reflection, it was felt that researcher knowledge contributed positively to the interpretation of data through being able to understand the particular scheme that participants were discussing.

For each participant, interviews took place on two occasions. Qualitative interviews are only able to uncover what participants recall or are willing to reveal about their experiences at a particular time, rather than realities. As such, they may reflect recall bias or inaccuracies. Participant knowledge of the researcher background may also have influenced what was disclosed. Readers can make choices about whether the identified themes resonate with their own intuitive understanding of such situations, 
which arguably can improve practice through the process of naturalistic generalisation. ${ }^{46}$

It is not known whether the experiences of those who declined to participate or dropped out of the study were different to those who took part. For example, we previously established that those aged under 55 years were less likely to engage in the first instance and more likely to dropout when they did. ${ }^{24}$ However, only one participant from this demographic completed a second interview. Additionally, this piece of work did not examine barriers to scheme access for who did not attend the initial consultation. Understanding this group, however, is critical for determining who current services are failing and why.

\section{CONCLUSION}

Overall, the data support arguments that ERSs can disproportionally engage with, and benefit, some disadvantaged groups. Importantly, they can successfully engage those with non-communicable diseases, and positively affect health and well-being. The value of current ERSs appears to be for those with social confidence and previous positive experiences of PA. Conversely, such schemes may fail for those who struggle to access social support due to varying health condition demands, or complex or impaired social circumstances. For those who are unable to adhere, feelings of ostracism and failure may further exacerbate outcome differentials. Ultimately, even programmes that target disadvantaged sub-groups (in the case of ERSs, those with non-communicable diseases) appear at risk of reinforcing inequalities. This study therefore highlights a need for services and systems that better provide for those with dynamic health and social circumstances.

\section{Author affiliations \\ ${ }^{1}$ School of Health and Social Care, Edinburgh Napier University, Edinburgh, UK ${ }^{2}$ Wolfson Research Institute for Health and Wellbeing Physical Activity Special Interest Group, Durham University, Durham, UK \\ ${ }^{3}$ Department of Sport and Exercise Sciences, Durham University, Durham, UK ${ }^{4}$ Department of Sport, Exercise and Rehabilitation, Faculty of Health and Life Sciences, Northumbria University, Newcastle upon Tyne, UK}

Acknowledgements Many thanks to ERS staff at Blyth Valley Arts and Leisure for helping with recruitment and organisation of interviews.

Contributors CLH contributed to the study design, data collection, data analysis and preparation of the final document. EJO contributed to data analysis and preparation of the final document. CJD-R and LJA contributed to study design, data analysis and preparation of the final document. All authors contributed to this paper and approved the final version.

Funding Blyth Valley Arts and Leisure was one of two providers of the exercise referral scheme studied and provided funding for a $\mathrm{PhD}$ to evaluate the service.

Competing interests CLH is a former employee of Blyth Valley Arts and Leisure and completed a PhD that was funded by the aforementioned company.

\section{Patient consent for publication Obtained.}

Ethics approval Northumbria University Faculty of Health and Life Sciences Ethics Committee (Ref: 15-03-131781)

Provenance and peer review Not commissioned; externally peer reviewed.

Data sharing statement № additional data are available.
Open access This is an open access article distributed in accordance with the Creative Commons Attribution Non Commercial (CC BY-NC 4.0) license, which permits others to distribute, remix, adapt, build upon this work non-commercially, and license their derivative works on different terms, provided the original work is properly cited, appropriate credit is given, any changes made indicated, and the use is non-commercial. See: http://creativecommons.org/licenses/by-nc/4.0/.

\section{REFERENCES}

1. Lee IM, Shiroma EJ, Lobelo F, et al. Effect of physical inactivity on major non-communicable diseases worldwide: an analysis of burden of disease and life expectancy. Lancet 2012;380:219-29.

2. Ding D, Lawson KD, Kolbe-Alexander TL, et al. The economic burden of physical inactivity: a global analysis of major non-communicable diseases. Lancet 2016;388:1311-24.

3. World Health Organisation. Global action plan for the prevention and control of non-communicable diseases 2013-2020. Geneva: World Health Organisation, 2013. http://africahealthforum.afro.who.int/IMG/ pdf/global action plan for the prevention and control_of ncds 2013-2020.pdf. (Accessed 05 Mar 2018).

4. World Health Organisation. Global status report on noncommunicable diseases, 2014. Geneva: World Health Organisation, 2014. http:// apps.who.int/iris/bitstream/10665/148114/1/9789241564854_eng. pdf. (Accessed 05 Mar 2018)

5. Eime RM, Charity MJ, Harvey JT, et al. Participation in sport and physical activity: associations with socio-economic status and geographical remoteness. BMC Public Health 2015;15:434.

6. Sievi NA, Senn O, Brack T, et al. Impact of comorbidities on physical activity in COPD. Respirology 2015;20:413-8.

7. Picorelli AM, Pereira LS, Pereira DS, et al. Adherence to exercise programs for older people is influenced by program characteristics and personal factors: a systematic review. J Physiother 2014;60:151-6.

8. Allender S, Cowburn G, Foster C. Understanding participation in sport and physical activity among children and adults: a review of qualitative studies. Health Educ Res 2006;21:826-35.

9. Borodulin K, Sipilä N, Rahkonen O, et al. Socio-demographic and behavioral variation in barriers to leisure-time physical activity. Scand $J$ Public Health 2016;44:62-9.

10. Kern ML, Reynolds CA, Friedman HS. Predictors of physical activity patterns across adulthood: a growth curve analysis. Pers Soc Psychol Bull 2010;36:1058-72.

11. Pan SY, Cameron C, Desmeules M, et al. Individual, social, environmental, and physical environmental correlates with physical activity among Canadians: a cross-sectional study. BMC Public Health 2009;9:21.

12. Zunft H-JF, Friebe D, Seppelt B, et al. Perceived benefits and barriers to physical activity in a nationally representative sample in the European Union. Public Health Nutr 1999;2-153-60.

13. Sowden SL, Raine R. Running along parallel lines: how political reality impedes the evaluation of public health interventions. A case study of exercise referral schemes in England. Journal of Epidemiology \& Community Health 2008;62:835-41.

14. Murphy SM, Edwards RT, Williams N, et al. An evaluation of the effectiveness and cost effectiveness of the National Exercise Referral Scheme in Wales, UK: a randomised controlled trial of a public health policy initiative. J Epidemiol Community Health 2012;66:745-53.

15. Sorenson J, Kragstrup J, Stovgaard T, et al. Exercise on prescription: a randomized study on the effect of counseling vs counseling and supervised exercise. Scand J Med Sci Sports 2008;18(3.

16. Gusi N, Reyes MC, Gonzalez-Guerrero JL, et al. Cost-utility of a walking programme for moderately depressed, obese, or overweight elderly women in primary care: a randomised controlled trial. BMC Public Health 2008;8:231.

17. Gallegos-Carrillo K, García-Peña C, Salmerón J, et al. Brief counseling and exercise referral scheme: a pragmatic trial in Mexico. Am J Prev Med 2017;52:249-59.

18. England PH. Identifying what works for local physical inactivity interventions. London: Public Health England, 2014. https://www. gov.uk/government/uploads/system/uploads/attachment_data/file/ 374560/Whatworksv1_2.pdf. (Accessed 05 Mar 2018).

19. Oliver EJ, Hanson CL, Lindsey IA, et al. Exercise on referral: evidence and complexity at the nexus of public health and sport policy. International Journal of Sport Policy and Politics 2016;8:731-6.

20. Campbell F, Holmes M, Everson-Hock E, et al. A systematic review and economic evaluation of exercise referral schemes in primary care: a short report. Health Technol Assess 2015;19:1-110.

21. National Institute for Health and Care Excellence. Physical activity; exercise referral schemes: National Institute for Health and Care 
Excellence, 2014. https://www.nice.org.uk/guidance/ph54/resources/ physical-activity-exercise-referral-schemes-pdf-1996418406085. (Accessed 05 Mar 2018).

22. Pavey TG, Taylor AH, Fox KR, et al. Effect of exercise referral schemes in primary care on physical activity and improving health outcomes: systematic review and meta-analysis. BMJ 2011;343:d6462.

23. Tong A, Sainsbury P, Craig J. Consolidated criteria for reporting qualitative research (COREQ): a 32-item checklist for interviews and focus groups. Int J Qual Health Care 2007:19:349-57.

24. Hanson CL, Allin LJ, Ellis JG, et al. An evaluation of the efficacy of the exercise on referral scheme in Northumberland, UK: association with physical activity and predictors of engagement. A naturalistic observation study. BMJ Open 2013;3:e002849.

25. Prochaska JO, Marcus BH. The transtheoretical model: Applications to exercise: In. Dishman RK, ed. Advances in exercise adherence. Champaign, IL, England: Human Kinetics, 1994:161-80.

26. Prochaska JO, DiClemente CC. Stages and processes of self-change of smoking: Toward an integrative model of change. J Consult Clin Psychol 1983;51:390-5.

27. Marshall MN. Sampling for qualitative research. Fam Pract 1996;13:522-6.

28. Strauss AL. Qualitative analysis for social scientists. Cambridge: Cambridge University Press, 1987.

29. Spencer L, Ritchie J, Lewis J, et al. Quality in qualitative evaluation: a framework for assessing research evidence. National Centre for Social Research 2003 http://dera.ioe.ac.uk/21069/2/a-qualityframework-tcm6-38740.pdf (Accessed 05 Mar 2018).

30. Festinger L. A Theory of Social Comparison Processes. Human Relations 1954;7:117-40.

31. Morgan F, Battersby A, Weightman AL, et al. Adherence to exercise referral schemes by participants - what do providers and commissioners need to know? A systematic review of barriers and facilitators. BMC Public Health 2016;16:1-11.

32. Pentecost C, Taket A. Understanding exercise uptake and adherence for people with chronic conditions: a new model demonstrating the importance of exercise identity, benefits of attending and support. Health Educ Res 2011;26:908-22.

33. De Lyon ATC, Neville RD, Armour KM. The role of fitness professionals in public health: a review of the literature. Quest 2017;69:313-30.
34. Dugdill L, Graham RC, McNair F. Exercise referral: the public health panacea for physical activity promotion? A critical perspective of exercise referral schemes; their development and evaluation. Ergonomics 2005;48:1390-410.

35. Gidlow C, Johnston LH, Crone D, et al. Socio-demographic patterning of referral, uptake and attendance in Physical Activity Referral Schemes. J Public Health 2007;29:107-13.

36. Sowden SL, Breeze E, Barber J, et al. Do general practices provide equitable access to physical activity interventions? Br J Gen Pract 2008;58:e1-e8.

37. Duda JL, Williams GC, Ntoumanis N, et al. Effects of a standard provision versus an autonomy supportive exercise referral programme on physical activity, quality of life and well-being indicators: a cluster randomised controlled trial. Int J Behav Nutr Phys Act 2014;11:10-15.

38. Sugai G, Horner RH, Dunlap G, et al. Applying positive behavior support and functional behavioral assessment in schools. J Posit Behav Interv 2000;2:131-43.

39. Gallagher R, Gallagher P, Zhang L, et al. Technology use and confidence in cardiac rehabilitation patients. Heart, Lung and Circulation 2016:25:S333.

40. Michie S, van Stralen MM, West R. The behaviour change wheel: a new method for characterising and designing behaviour change interventions. Implement Sci 2011;6:42.

41. Martín-Borràs $C$, Giné-Garriga $M$, Puig-Ribera $A$, et al. $A$ new model of exercise referral scheme in primary care: is the effect on adherence to physical activity sustainable in the long term? A 15-month randomised controlled trial. BMJ Open 2018;8:e017211.

42. Hawkins J, Madden K, Fletcher A, et al. Development of a framework for the co-production and prototyping of public health interventions. BMC Public Health 2017;17:689.

43. Buckley BJR, Thijssen DHJ, Murphy RC, et al. Making a move in exercise referral: co-development of a physical activity referral scheme. J Public Health 2018;40:e586-e593.

44. Creswell JW, Miller DL. Determining validity in qualitative inquiry. Theory Pract 2000;39:124-30.

45. Gair S. Feeling their stories: Contemplating empathy, insider/outsider positionings, and enriching qualitative research. Qual Health Res 2012;22:134-43.

46. Stake RE, Trumbull DJ. Naturalistic generalizations. Review Journal of Philosophy and Social Science 1982;7:1-12. 